\title{
Diastolic Heart Failure: A Review and Primary Care Perspective
}

\author{
Sean Haney, MD, Denise Sur, MD, and Zijian Xu, MD, PhD
}

Previously the subject of much debate, there is now consensus that diastolic heart failure (DHF) represents a distinct form of heart failure. Epidemiologic data indicate that DHF is common. Indeed, there is evidence that, among elderly persons, DHF is more common than systolic heart failure (SHF). Like SHF, DHF is associated with significant morbidity, mortality, and cost; however, few clinical trials focusing on isolated DHF have been completed. Much of the treatment of DHF is based on current concepts of the pathophysiology of DHF, small clinical studies, and experience gained from treating patients with SHF. The diagnosis of DHF is clinical; data supporting the establishment of a diagnosis of DHF are limited. Differences exist in prognosis and treatment between diastolic and systolic heart failure. This article reviews diastolic heart failure with emphasis on evidence-based management, aimed at primary care physicians who routinely provide care to patients with DHF. (J Am Board Fam Pract 2005;18:189-98.)

In addition to being a major cause of morbidity and mortality, congestive heart failure (CHF) is a leading cause of hospitalization of elderly persons in the United States and is estimated to cost up to $\$ 40$ billion per year. ${ }^{1}$ Clinical trials regarding $\mathrm{CHF}$ have been overwhelmingly directed toward patients with systolic heart failure (SHF) (ie, heart failure $[\mathrm{HF}]$ syndrome associated with a reduced left ventricle ejection fraction [LVEF]). HF syndrome, however, may also occur in patients with preserved LVEF but with abnormalities in left ventricular diastolic function. Such a heart failure (HF) syndrome (ie, diastolic heart failure $[\mathrm{DHF}]$ ) is now widely accepted among cardiologists as representing a distinct form of $\mathrm{HF}$.

DHF is caused by left ventricular diastolic dysfunction (DD), leading to increased resistance to left ventricular filling and eventually resulting in HF syndrome. Certain conditions such as ischemia, left ventricular hypertrophy, hypertension, and aortic stenosis predispose to DD. ${ }^{2,3}$ Impaired ven-

Submitted, revised, 26 January 2005.

From the Department of Family Medicine, Division of Sports Medicine, Kaiser Permanente, Los Angeles, California (SH), and Department of Family Medicine (DS) and Division of Cardiology, Department of Medicine (ZX), David Geffen School of Medicine at UCLA, Santa Monica, California. Address correspondence to Dr. Sean Haney, Department of Family Medicine, Division of Sports Medicine, Kaiser Permanente, 4950 Sunset Boulevard, Los Angeles, CA 90027 (e-mail: sean.x.haney@kp.org). tricular relaxation and increased ventricular stiffness are mechanisms by which these conditions lead to DD and subsequently to $\mathrm{DHF} .^{2-4} \mathrm{DD}$ itself, without clinical evidence of HF, has been associated with increased all-cause mortality and increased risk of developing $\mathrm{CHF}^{5}$ Thus, DD may be viewed as a precursor of DHF. DD is universally present in patients with significant left ventricular systolic dysfunction. ${ }^{6}$

The symptoms of CHF may be identical whether failure is secondary to systolic or diastolic dysfunction. ${ }^{7}$ There are, however, differences in the prognosis, characteristics of the patients, pathophysiology, and treatment between the 2 conditions.

There have been multiple randomized controlled trials (RCTs) for the treatment of SHF in the recent years. Such trials have helped to establish evidence-based treatment guidelines and have led to improved outcomes for patients with SHF. Current management of DHF, however, is based largely on pathophysiological principles, clinical experience, and small clinical studies. RCTs designed to specifically address DHF are under way, and one such RCT has recently been completed. ${ }^{8}$ As our understanding of the DHF improves and additional RCTs are completed, treatment of DHF will continue to evolve. Because most patients with DHF are first encountered by primary care physicians, it is important for them to appreciate DHF as 
a condition that is distinct from SHF, that has significant morbidity and mortality, and that requires a different management strategy compared with SHF.

\section{Epidemiology}

Studies indicate that $30 \%$ to $55 \%$ of patients with $\mathrm{CHF}$ have preserved systolic function, defined as LVEF of $45 \%$ or greater. ${ }^{9-13}$ In a large populationbased study, $8 \%$ of persons older than 65 years were found to have $\mathrm{HF}$, and $55 \%$ of the patients with HF were noted to have normal LVEF. ${ }^{10}$ The same study found patients with DHF to be twice as likely to have diabetes mellitus as asymptomatic control subjects. ${ }^{10}$ In addition, patients with DHF are more likely to be older and female and to have a history of hypertension..$^{9,10,14}$

\section{Morbidity and Mortality}

Similar reductions in quality of life, as measured on standard HF indices, have been noted for patients with DHF and SHF. ${ }^{15}$ Patients with DHF or SHF have significantly decreased peak exercise performance compared with healthy control subjects. Exercise performance, as measured by lactate levels, is also markedly decreased in both DHF and SHF patients compared with healthy control subjects. ${ }^{15}$ Furthermore, for patients hospitalized with clinical evidence of $\mathrm{CHF}$, readmission rates for patients with an LVEF greater than $50 \%$ are similar to those with LVEF less than $50 \% .{ }^{16}$

DHF is associated with significant annual mortality, but the mortality may be less than that with SHF. The Veterans Administration Cooperative Study, a study of hospitalized CHF patients, found that CHF patients with preserved $\mathrm{EF}$ had an annual mortality of $8 \%$; those with a reduced EF had a $19 \%$ annual mortality. ${ }^{17}$ Analysis of Framingham data also demonstrated a significant difference in mortality between patients with DHF and SHF; there was an annual mortality for DHF of $8.7 \%$ versus $3.0 \%$ for age-matched control subjects, and for SHF $18.9 \%$ versus $4.1 \%$ for age-matched control subjects. ${ }^{12}$ Furthermore, this communitybased study found that $51 \%$ of CHF patients had preserved EF. ${ }^{12}$ Results from the United Kingdom Heart Failure Evaluation and Assessment of Risk Trial (UK-HEART) study indicate a 5-year mortality of $25.2 \%$ for DHF versus $41.5 \%$ for SHF. ${ }^{11}$ In contrast, a study of newly diagnosed CHF in
Olmsted County found no difference in mortality between those with preserved and reduced EF.? The discrepancy between these studies may be the result of older age at diagnosis in the Olmsted county study, where $49 \%$ of newly diagnosed CHF subjects were more than 80 years old.?

\section{Pathophysiology}

Diastole starts with isovolemic relaxation, which is an energy-dependent process, followed by rapid ventricular filling, and finally atrial contraction. Factors affecting either phase may contribute to DD. Impairment of diastolic filling as a result of DD leads to elevated pulmonary pressures and ultimately pulmonary congestion or edema, which gives rise to the clinical symptoms and signs of diastolic heart failure. DD may develop from factors either intrinsic or extrinsic to the left ventricle. ${ }^{2}$ Intrinsic factors causing DD occur primarily as one of 2 mechanisms: (1) impaired relaxation; (2) increased stiffness. ${ }^{2}$ Extrinsic factors, such as pericardial restriction, may also cause DD. ${ }^{18}$

Ventricular diastolic relaxation, an energy-dependent process, may be impaired by decreased energy availability or by changes in calcium homeostasis. $^{2,18}$ ATP is required for actin-myosin crossbridge dissociation and the reuptake of calcium into the sarcoplasmic reticulum. ${ }^{2}$ Conditions associated with decreased ATP availability, such as ischemia, increased diastolic calcium concentration, or a delay in the decline of diastolic calcium concentration, may impair relaxation., ${ }^{2,18,19} \mathrm{Re}$ moval of calcium from the cytosol may be delayed by decreased activity of sarcoplasmic reticulum calcium ATPase (SERCA) or an increased level of activity of phospholamban (a SERCA inhibitory protein). ${ }^{18,19}$ Decreased SERCA and increased phospholamban may occur with ventricular hypertrophy secondary to hypertension or aortic sclerosis. ${ }^{20}$

Ventricular hypertrophy may increase ventricular stiffness and thereby impair diastolic function. ${ }^{2,3}$ Ventricular stiffness increases when wall thickness relative to chamber size increases. ${ }^{2}$ This type of hypertrophy, also known as concentric hypertrophy, is often secondary to hypertension or aortic stenosis. ${ }^{2}$ Disproportionate growth of the nonmyocardial extracellular matrix, secondary to the aforementioned conditions, leads to left ventricular stiffness. The hypertrophied heart fails to completely relax, leading to increased left ventricular filling 
pressures. ${ }^{21}$ Ventricular hypertrophy secondary to exercise training results in proportional growth of muscular and nonmuscular elements and is not associated with diastolic abnormalities. ${ }^{22}$

Activation of the renin-angiotensin-aldosterone system is a key in the development myocardial fibrosis and stiffness. Besides stimulating vasoconstriction and salt and water retention, angiotensin II stimulates increased collagen deposition. ${ }^{23}$ Aldosterone, a mineralocorticoid, stimulates collagen deposition and sodium retention. ${ }^{23}$ Changes in the extracellular matrix, particularly in fibrillar collagen, a key component of the extracellular matrix, contribute to ventricular hypertrophy and with it DD. ${ }^{18}$ Inhibition of renin-angiotensin-aldosterone system has been demonstrated to reduce myocardial stiffness and to lead to regression of myocardial fibrosis. ${ }^{24,25}$ Hypertension, diabetes mellitus, coronary artery disease, aortic stenosis, and cardiomyopathy are common conditions that predispose to the development of DD. . $^{2,3,26}$

\section{B-Type Natriuretic Peptide}

B-type natriuretic peptide (BNP), a cardiac neurohormone released by the ventricles in response to volume expansion and pressure overload, has recently emerged as a marker for $\mathrm{HF}^{27} \mathrm{BNP}$ is elevated in DHF as well as SHF; mean BNP levels are 20 times greater in patients with DHF than in matched control subjects. ${ }^{14} \mathrm{BNP}$ is more markedly elevated in SHF. ${ }^{14}$ Among persons with DD, BNP is highest among those with a restrictive filling pattern; as such, it correlates with Doppler indices of DD. ${ }^{27}$ Several studies report the use of BNP in the diagnosis of DHF and SHF in the primary care, urgent care, and emergency department settings. $^{28,29}$ There is, however, overlap in BNP levels between persons with healthy cardiac function and those with DHF. ${ }^{15}$ There are insufficient data to make a recommendation regarding the utility of $\mathrm{BNP}$ in DHF.

\section{Diagnosis of DHF}

The diagnosis of DHF is primarily clinical. The American College of Cardiology and American Heart Association Practice Guidelines reflect this: "In practice, the diagnosis of DHF is generally based on the finding of typical symptoms and signs of $\mathrm{HF}$ in a patient who is shown to have a normal left ventricular ejection fraction and no valvular abnormalities on echocardiography." ${ }^{30}$ However, evidence of left ventricular DD may be obtained by heart catheterization or echocardiography. Catheterization may demonstrate elevated left ventricular diastolic pressures with normal ventricular volumes and systolic function consistent with DD. Although catheterization is the standard for diagnosing DD, it is expensive and invasive. Echo-Doppler assessment of transmitral velocities is a convenient and effective way of assessing diastolic function (Figures 1 to 4$)$.

Measurement of diastolic function is complex and dependent on loading conditions of the heart. Multiple parameters may be measured. Two such parameters are transmitral velocity and deceleration time. Blood flow across the mitral valve occurs in 2 phases: an early transmitral flow (E wave) and a late flow with atrial contraction (A wave). The relative contribution of each is expressed as a ratio (E/A). An E/A ratio less than 0.75 or greater than 1.5 indicates DD. DD may be present with an E/A ratio between 0.75 and 1.5 if other parameters, such as the deceleration time, are abnormal. Patterns of diastolic function are schematically illustrated in Figure 1. As relaxation is impaired and ventricular pressure falls more slowly, DD develops (Figures 1 and 3). As a result, the $\mathrm{E}$ wave decreases and the ratio is less than 0.75 . As DD progressively worsens, a pattern that appears normal, or a pseudo-normal pattern, may develop (Figure 1). This

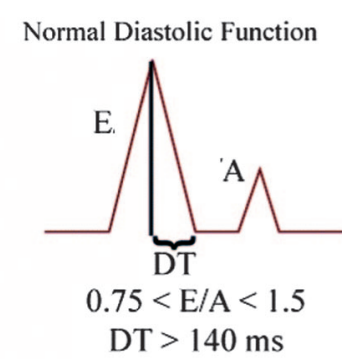

Moderate Diastolic Dysfunction (Pseudonormal)

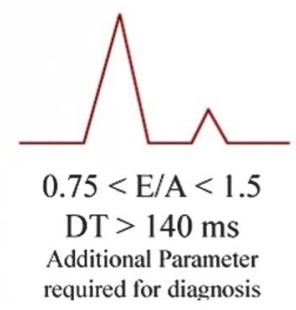

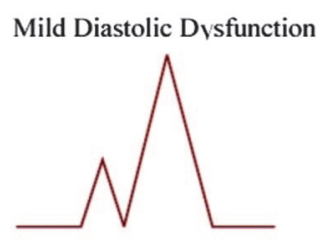

$\mathrm{E} / \mathrm{A} \leq 0.75$

$\mathrm{DT} \geq 230$

Severe Diastolic Dysfunction (Restrictive)

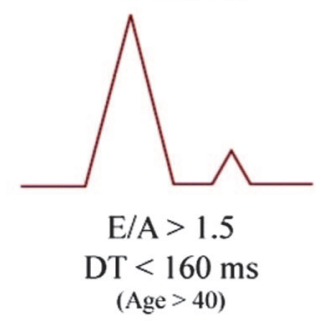

(Age $>40)$

Figure 1. Diastolic parameters. 


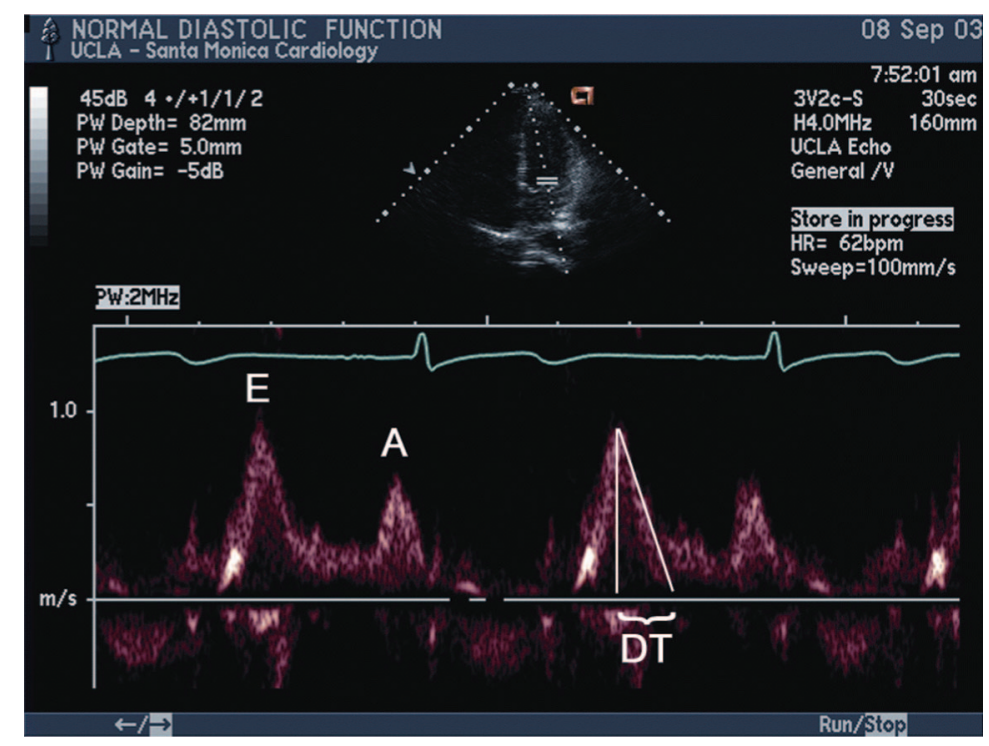

Figure 2. Normal diastolic function. Doppler recordings of normal transmitral filling velocities. An E/A wave ratio between 0.75 and 1.5 and deceleration time (DT) greater than 140 milliseconds is characteristic of a normal filling pattern.

pseudo-normal pattern is characterized by abnormally high pressures and other abnormal Doppler parameters. Finally, with reduced chamber compliance and severe DD, a restrictive pattern develops (Figures 1 and 4).

There have been attempts to standardize the diagnostic criteria for DHF. The European Society of Cardiology proposed criteria for DHF based on diastolic values obtained via cardiac catheterization or echocardiography. ${ }^{31}$ Some of these measures, however, are not routinely obtained, and their interpretation is complex, which may limit their usefulness. Another study found that an objective measure of diastolic function may not be necessary to establish a diagnosis of DHF. In a prospective study of patients with $\mathrm{EF} \geq 50 \%$ who met the Framing-

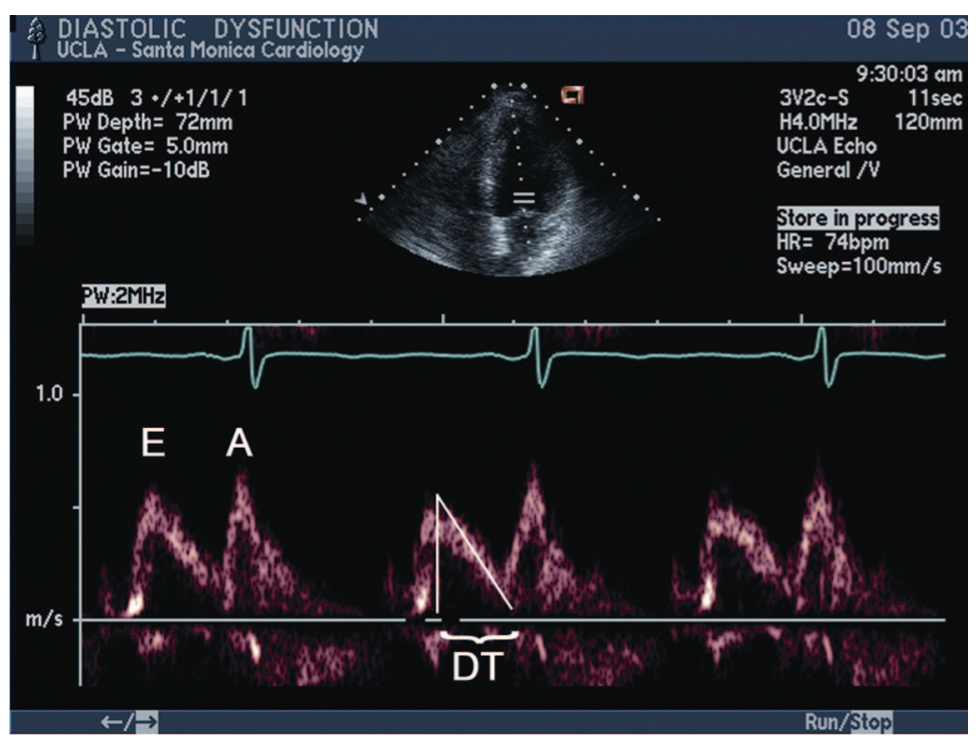

Figure 3. Mild diastolic dysfunction. Doppler recordings of transmitral filling velocities indicating inpaired relaxation. In this pattern, the $\mathrm{E} / \mathrm{A}$ wave ratio is less than 0.75 and deceleration time (DT) is greater than 230 milliseconds. 


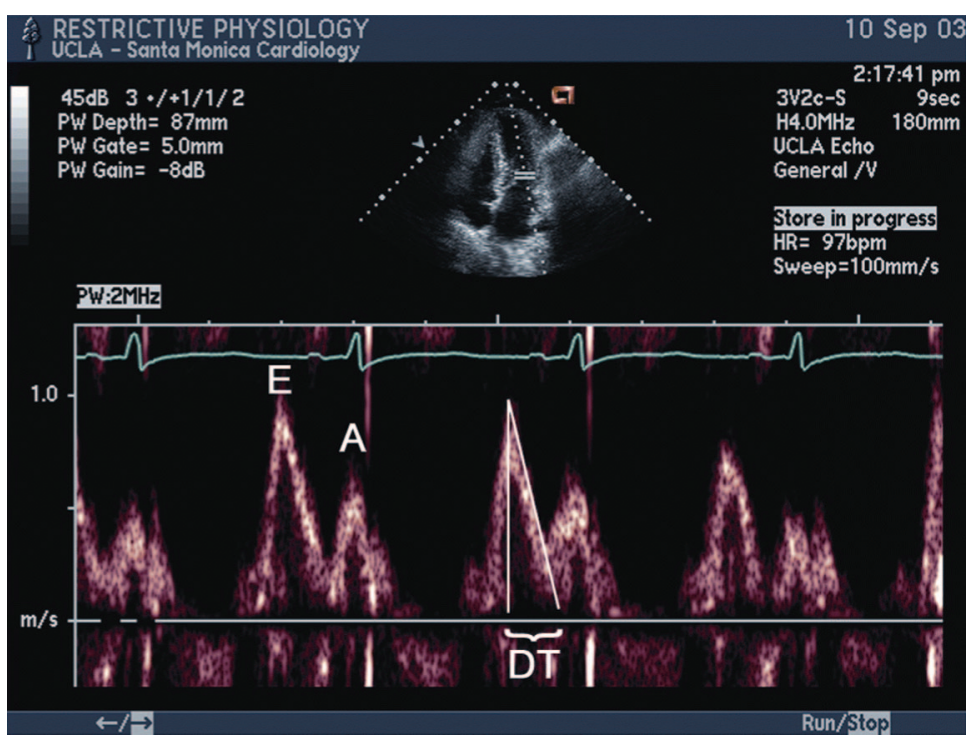

Figure 4. Restrictive pattern. Doppler recordings of transmitral filling velocities in a restrictive filling pattern. An E/A wave ratio greater than 1.5 and deceleration time (DT) less than 160 milliseconds indicates restrictive filling pattern.

ham criteria for CHF and who underwent catheterization and Doppler-Echo, all subjects were found to have either elevated catheterization pressures or diastolic abnormalities on Doppler. ${ }^{32}$ This study, however, was nonblinded and required only a single abnormal diastolic parameter to confirm a DHF diagnosis. Because the data regarding establishing a diagnosis of DHF are limited, the diagnosis is primarily clinical.

\section{Principles of Treatment}

Until mechanism-targeted treatment becomes available, the current strategy for the management of DHF focuses on symptom relief and modification of underlying causes of DHF (Table 1). The clinical symptoms of DHF are caused primarily by elevated left ventricular diastolic pressures, resulting in pulmonary and systemic congestion or edema. Relief of pulmonary or systemic congestion may be achieved by reducing total systemic volume and, more importantly, enhancing left ventricular diastolic filling. Although both nonpharmacological (fluid and salt restriction) and pharmacological (diuretics or nitrates) means may be helpful in reducing total systemic volume (Strength of Recommendation Taxonomy [SORT] level A), targeting treatment of a variety of underlying cardiac conditions is also indicated. ${ }^{30}$ Hypertension and ischemia, both of which significantly impair diastolic function should be treated immediately (SORT level C). ${ }^{30}$ Loss of atrioventricular synchrony, as occurs in atrial flutter and fibrillation, which may further reduce diastolic filling and trigger DHF, may require immediate correction. Tachycardia, which increases myocardial oxygen demand and simultaneously decreases coronary perfusion, is poorly tolerated in patients with DD and may exacerbate DHF (SORT level C). ${ }^{33}$ Targeting underlying causes of DHF, such as coronary heart disease, valve conditions, and hypertension, is vital for optimal management. Exercise has been shown to reduce symptoms in patients with $\mathrm{DHF}^{34} \mathrm{Al}$ though data regarding outcomes do not currently exist, exercise initiated as part of a cardiac rehabilitation program may prove to be an important part of a multidisciplinary approach in the treatment of patients with DHF. It is important to note that for primary care physicians, hypertension is the most common underlying cause of DD; therefore, aggressive management of hypertension is essential in the prevention and management of DD and DHF (SORT level C).

\section{Specific Drugs}

Most drugs used in treating SHF are also useful in the treatment of DHF; however, with the exception of the Candesartan in Heart failure Assessment of Reduction in Mortality and Morbidity (CHARM) 
Table 1. Principles of Management of Diastolic Heart Failure*

\begin{tabular}{|c|c|}
\hline Goal & Therapy \\
\hline Reduction of congestion & $\begin{array}{l}\text { Salt restriction } \\
\text { Less than } 2 \mathrm{~g} \text { daily } \\
\text { Diuretics } \\
\text { Thiazides and loop diuretics } \\
\text { ACEIs } \\
\text { Enalapril } \\
\text { Lisinopril } \\
\text { ARBs } \\
\text { Candesartan } \\
\text { Losartan }\end{array}$ \\
\hline $\begin{array}{l}\text { Maintenance of rate } \\
\text { control }\end{array}$ & $\begin{array}{l}\beta \text {-blockers } \\
\text { Atenolol, metoprolol } \\
\text { Calcium channel blockers } \\
\text { Diltiazem, verapamil } \\
\text { Conversion of atrial fibrillation } \\
\text { Atrioventricular pacing }\end{array}$ \\
\hline $\begin{array}{l}\text { Optimal management of } \\
\text { hypertension }\end{array}$ & $\begin{array}{l}\text { Antihypertensive agents } \\
\beta \text {-blockers } \\
\text { Calcium channel blockers } \\
\text { Diuretics } \\
\text { ACEIs } \\
\text { ARBs } \\
\text { Spironolactone }\end{array}$ \\
\hline $\begin{array}{c}\text { Prevention and treatment } \\
\text { of myocardial ischemia }\end{array}$ & $\begin{array}{l}\beta \text {-blockers } \\
\text { Atenolol, metoprolol } \\
\text { Calcium channel blockers } \\
\text { Diltiazem, verapamil } \\
\text { Nitrates } \\
\text { Isosorbide dinitrate } \\
\text { Isosorbide mononitrate } \\
\text { Revascularization } \\
\text { Percutaneous transluminal } \\
\text { coronary angioplasty, coronary } \\
\text { artery bypass surgery }\end{array}$ \\
\hline
\end{tabular}

* This information is based on the authors' experience and a review of the literature regarding diastolic heart failure (DHF). It should be emphasized that the literature is incomplete. With the exception of the CHARM study, no randomized controlled trial (RCT) has specifically evaluated the efficacy of a specific agent in the treatment of DHF. Most studies were designed to evaluate a drug in the treatment of systolic heart failure (SHF) and were not specifically designed to assess their efficacy in DHF patients. These studies and an understanding of the pathophysiology of DHF form the basis of current discussion of therapy in the cardiology literature.

ACEI, angiotensin-converting enzyme inhibitor; ARB, angiotensin receptor blocker; $\beta$-blocker, $\beta$-adrenergic receptor blocker.

study, a lower level of evidence, including understanding of the pathophysiology of DHF, support their use. In addition, there are significant differences in the dosage and duration of these drugs between SHF and DHF. Table 2 highlights the differences in treatment between SHF and DHF.

Data support the use of angiotensin-converting enzyme inhibitors (ACEIs) and angiotensin receptor blockers (ARBs) for the treatment of DHF. As in the treatment of SHF, initial therapy should begin with an ACEI when indicated. In patients with SHF, ACEIs have been shown to decrease mortality and hospital admissions and to improve exercise tolerance and quality of life (SORT level B). ${ }^{35,36}$ ACEIs have been shown to decrease LV hypertrophy and increase LV relaxation. ${ }^{37,38} \mathrm{In}$ deed, in a study of elderly patients with New York Heart Association class III HF with EF of greater than $50 \%$, enalapril significantly improved diastolic filling, exercise tolerance, LV hypertrophy LVEF, and HF functional class (SORT level 2). ${ }^{39}$ Lisinopril was shown in a small but extensive clinical study incorporating echocardiography and left heart catheterization with endomyocardial biopsy to lead to regression of myocardial fibrosis, accompanied by improvement of diastolic parameters. ${ }^{24}$ The efficacy of ACEIs may be attributable in part to their interference with the neuroendocrine system.

The data to support the use of ARBs in DHF include a number of clinical studies. In the Losartan Intervention for Endpoint Reduction in Hypertension (LIFE) study, losartan-based hypertensive treatment was associated with regression of $\mathrm{LV}$ mass and improved diastolic filling parameters. ${ }^{40}$ Losartan has been shown to dampen the hypertensive response, improve exercise tolerance, and improve quality of life in patients with DD (SORT level 2). ${ }^{41}$ In the recent and only completed RCTs so far that specifically address $\mathrm{HF}$ patients with preserved LVEF ( $\geq 40 \%$ ), the CHARM-Preserve trial, candesartan was associated with a $29 \%$ relative risk reduction in $\mathrm{CHF}$ admissions (SORT level 1). ${ }^{8}$ Candesartan treatment, however, did not result in reduced mortality. Nevertheless, the findings of the CHARM-Preserve trial support the use of ARBs in the treatment of DHF.

$\beta$-Adrenergic receptor blockers ( $\beta$-blockers) are frequently used for the treatment of DHF. In theory, $\beta$-blockers may be expected to improve outcomes for patients with DHF by a number of mechanisms: slowing heart rate (thereby allowing increasing left ventricular filling time and reducing myocardial oxygen demand), improving hypertension, regression of left ventricular hypertrophy, and direct inhibition of renin release (SORT level C). ${ }^{42}$ $\beta$-Blockers have been shown to improve diastolic parameters in patients with SHF. ${ }^{42}$ There are significant differences in the use of $\beta$-blockers in DHF and SHF. In SHF, $\beta$-blockers are started at very small doses and progressively titrated over weeks or months, as tolerated, to fixed doses. In 


\begin{tabular}{|c|c|c|}
\hline & Similarities & Differences \\
\hline$\beta$-Blockers & $\begin{array}{l}\text { - Used to treat HTN } \\
\text { - May be used to rate control patients with } \\
\text { atrial fibrillation or flutter }\end{array}$ & $\begin{array}{l}\text { - Used to modify left ventricular remodeling to } \\
\text { prolong survival in SHF } \\
\text { - Titrated slowly to specific dose in SHF } \\
\text { - In DHF, used to decrease heart rate and } \\
\text { prolong diastole to reduce symptoms } \\
\text { - DHF titrated more rapidly to response than } \\
\text { in SHF }\end{array}$ \\
\hline $\begin{array}{l}\text { Calcium channel } \\
\text { blockers }\end{array}$ & - May be used to treat HTN & $\begin{array}{l}\text { - Generally avoided in treating SHF } \\
\text { - Shown to improve diastolic parameters and } \\
\text { exercise tolerance } \\
\text { - Particularly useful in setting of atrial } \\
\text { fibrillation }\end{array}$ \\
\hline Diuretics & $\begin{array}{l}\text { - Symptom reduction through volume reduction } \\
\text { in acute and chronic settings } \\
\text { - May be used to treat HTN }\end{array}$ & $\begin{array}{l}\text { - Patients with SHF more likely to require } \\
\text { higher doses and long-term therapy } \\
\text { - Patients with DHF more likely to tolerate } \\
\text { weaning } \\
\text { - Judicious use in DHF as patients may be } \\
\text { preload-dependent }\end{array}$ \\
\hline Nitrates & $\begin{array}{l}\text { - Used to treat patients with ischemic heart } \\
\text { disease } \\
\text { - Contribute to volume reduction }\end{array}$ & \\
\hline ACEIs & $\begin{array}{l}\text { - May be used to treat HTN } \\
\text { - Associated with LV regression and } \\
\text { experimental data suggest improved } \\
\text { myocardial relaxation }\end{array}$ & $\begin{array}{l}\text { - Ample data to support use in SHF although } \\
\text { relatively few studies in patients with DHF }\end{array}$ \\
\hline ARBs & $\begin{array}{l}\text { - May be used to treat hypertension } \\
\text { - Associated with LV regression and } \\
\text { experimental data suggest improved } \\
\text { myocardial relaxation }\end{array}$ & - Few trials in patients with DHF \\
\hline Spironolactone & $\begin{array}{l}\text { - Aldosterone, which promotes fluid retention, } \\
\text { myocardial, and vascular fibrosis is blocked. } \\
\text { May have benefit in both DHF and SHF } \\
\text { treatment }\end{array}$ & $\begin{array}{l}\text { - Shown to improve symptoms, decrease risk of } \\
\text { death, and hospitalization in SHF }\end{array}$ \\
\hline Digoxin* & $\begin{array}{l}\text { - Beneficial for rate control in patients with } \\
\text { atrial fibrillation or flutter }\end{array}$ & $\begin{array}{l}\text { - Used to improve ejection fraction in patients } \\
\text { with SHF } \\
\text { - May increase intracellular calcium } \\
\text { concentration, which may impair diastolic } \\
\text { relaxation }\end{array}$ \\
\hline
\end{tabular}

* Digoxin use is controversial in the treatment of DHF.

$\beta$-blocker, $\beta$-adrenergic receptor blocker; ACEI, angiotensin-converting enzyme inhibitor; ARB, angiotensin receptor blocker; HTN, hypertension; SHF, systolic heart failure; DHF, diastolic heart failure; LV, left ventricle.

DHF, $\beta$-blockers are usually titrated much more rapidly to moderate or high doses.

Although the use of calcium channel blockers (CCBs) in SHF is generally avoided, CCBs are potentially useful in the treatment of DHF. Through their antihypertensive effect and afterload reduction, CCBs may lead to regression of $\mathrm{LV}$ hypertrophy and improvement of passive filling. The negative chronotropic effect of the nondihydropyridine CCBs may enhance diastolic filling by prolonging diastole. They are particularly useful in patients with atrial flutter or atrial fibrillation with rapid ventricular response. Verapamil and nifedipine have been shown to improve diastolic param- eters. ${ }^{3,43}$ In addition, verapamil has been shown to improve symptoms and exercise capacity in patients with hypertrophic cardiomyopathy, a condition characterized by $\mathrm{DD},{ }^{43,44}$ and to improve exercise capacity, peak LV filling, and heart failure scores in patients with $\mathrm{DHF} .{ }^{45}$ Because there is a lack of evidence of mortality benefit in SHF, CCBs should be considered a second line agent for DHF. Nondihydropyridine CCBs (verapamil and diltiazem) are the agents of choice. Dihydropyridine agents (nifedipine), which may cause reflexive tachycardia, may be used for treating conditions such as hypertension or angina but should not be used for the treatment of DHF itself. 
Diuretics may be useful in the treatment of DHF because LV filling pressures are commonly increased in DHF. Diuretics reduce total blood volume, resulting in a reduction of $\mathrm{LV}$ diastolic volume and pressures (SORT level A). Patients with DHF, however, may be preload-dependent; ie, they require higher ventricular filling pressures to generate low-normal to normal cardiac output. ${ }^{46}$ One study reports a $10 \%$ reduction in cardiac output after preload-reducing therapy in $\mathrm{DHF}^{47} \mathrm{In}$ the case of acute pulmonary congestion, vigorous diuresis may be required, although not nearly to the same extent as in SHF. Because patients require higher ventricular pressures to maintain cardiac output, over diuresis may impair ventricular filling, decreasing cardiac output. Long-term use of diuretics in DHF, unlike SHF, is often unnecessary. Withdrawal of furosemide in patients with DHF without overt pulmonary congestion was shown, in a small placebo-controlled study, to lead to improvement of blood pressure homeostasis without increasing HF symptoms (SORT level 2). ${ }^{48} \mathrm{Di}-$ uretics are useful agents in treating hypertension, which is a common trigger for exacerbation of DHF (SORT level A). Compared with SHF, DHF patients require lower doses of diuretics and may tolerate their withdrawal.

Although digoxin has historically been a mainstay in the treatment of SHF, there are little data to support it; in theory, there are reasons against its use in DHF. In patients with preserved EF, digoxin may, in theory, be detrimental by increasing contractility and oxygen consumption. In addition, digoxin hinders intracellular calcium clearance in diastole, which may impair diastolic relaxation. Digoxin may play an important role in controlling the ventricular rate in patients with atrial fibrillation or flutter, especially when combined with CCBs or $\beta$-blockers.

Finally, aldosterone inhibitors may play a role in the treatment of DHF. Because aldosterone stimulates collagen deposition and cardiac fibrosis, blocking aldosterone may contribute to improved cardiac function. The Randomized Aldactone Evaluation Study demonstrated decreased mortality among patients with severe SHF. ${ }^{49}$ In patients with hypertension and diastolic dysfunction, canrenone (the main active metabolite of spironolactone) was shown to improve diastolic parameters not accounted for by changes in blood pressure or left ventricular mass. ${ }^{50}$

\section{Conclusion}

DHF is common and may account for more than $50 \%$ of HF cases among the elderly. ${ }^{9,13}$ As with SHF, DHF is associated with significant morbidity and mortality. There are differences in the pathogenesis, prognosis, and treatment of DHF and SHF. The diagnosis of DHF is clinical; data supporting diagnostic criteria are lacking. Current clinical management is based on symptom relief and modification of underlying cardiac conditions. Maintenance of euvolemia, rate control of atrial fibrillation, and management of hypertension are key elements of this. Evidence from large scale RCTs has been scarce, but several clinical trials are under way. As more RCTs in patients with DHF are completed, treatment will further evolve. It is therefore important for primary care physicians to recognize the difference between DHF and SHF and modify their approach to treatment of patients with DHF as indicated.

We thank Andrew Lee and Drs. Anurag Relan and Carol Stewart for assistance with the manuscript.

\section{References}

1. O'Connel JB, Bristow MR. Economic impact of heart failure in the United States: time for a different approach. J Heart Lung Transplant 1994;13:S10712.

2. Litwin S, Grossman W. Diastolic dysfunction as a cause of heart failure. J Am Coll Cardiol 1993;22 Suppl A:49A-55A.

3. Bonow RO, Udelson JE. Left ventricular diastolic dysfunction as a cause of congestive heart failure: mechanism and management. Ann Intern Med 1992; 117:502-10.

4. Zile M, Brutsaert D. New concepts in diastolic dysfunction and diastolic heart failure: part I: diagnosis, prognosis, and measurements of diastolic function. Circulation 2002;105:1387-93.

5. Redfield MM, Jacobsen SJ, Burnett JC, et al. Burden of systolic and diastolic ventricular dysfunction in the community: appreciating the scope of the heart failure epidemic. JAMA 2003;289:194-202.

6. Nishimura R, Tajik J. Evaluating diastolic filling of left ventricle in health and disease: Doppler echocardiography is the clinician's Rosetta stone. J Am Coll Cardiol 1997;30:8-18.

7. Thomas JT, Kelly RF, Thomas SJ, et. al. Utility of history, physical examination, electrocardiogram, and chest radiograph for differentiating normal from decreased systolic function in patients with heart failure. Am J Med 2002;112:437-45.

8. Yusuf S, Pfeffer M, Swedberg K, et al. Effects of 
candesartan in patients with chronic heart failure and preserved left-ventricular ejection fraction: the CHARM-Preserved Trial. Lancet 2003;362:777-81.

9. Senni M, Tribouilloy CM, Rodeheffer RJ, et al. Congestive heart failure in the community: a study of all incident cases in Olmsted County, Minnesota, in 1991. Circulation 1998;98:2282-9.

10. Kitzman DW, Gardin JM, Gottdiener JS, et al. Importance of heart failure with preserved systolic function in patients $\geq 65$ years of age. Am J Cardiol 2001;87:413-9.

11. MacCarthy PA, Kearney MT, Nolan J, et al. Prognosis in heart failure with preserved left ventricular systolic function: prospective cohort study. BMJ 2003;327:78-9.

12. Vasan RS, Larson MG, Benjamin EJ, Evans JC, Reiss CK, Levy D. Congestive heart failure in subjects with normal versus reduced left ventricular ejection fraction: prevalence and mortality in a population-based cohort. J Am Coll Cardiol 1999;33: $1948-55$.

13. Aurigemma GP, Gottdiener JS, Shemanski L, Gardin J, Kitzman DW. Predictive value of systolic and diastolic function for incident congestive heart failure in the elderly: the Cardiovascular Health Study. J Am Coll Cardiol 2001;37:1042-8.

14. Devereux RB, Roman MJ, Liu JE, et al. Congestive heart failure despite normal left ventricular systolic function in population-based sample: the Strong Heart Study. Am J Cardiol 2000;86:1090-6.

15. Kitzman DW, Little WC, Brubaker PH, et al. Pathophysiological characterization of isolated diastolic heart failure in comparison to systolic heart failure. JAMA 2002;288:2144-50.

16. Philbin EF, Rocco TA, Lindenmuth NW, Ulrich K, Jenkins PL. Systolic versus diastolic heart failure in community practice: clinical features, outcomes, and the use of angiotensin-converting enzyme inhibitors. Am J Med 2000;109:605-13.

17. Cohn J, Johnson G, Veterans Administration Cooperative Study Group. Heart failure with normal ejection fraction: the V-HeFT Study. Circulation 1990;81 Suppl III:48-53.

18. Zile M, Brutsaert D. New concepts in diastolic dysfunction and diastolic heart failure: part II: causal mechanism and treatment. Circulation 2002;105:1503-8.

19. Apstein CS, Morgan JP. Cellular mechanism underlying left ventricular diastolic failure. In: Gaasch WH, LeWinter MM, editors. Left ventricular diastolic dysfunction and heart failure. Philadelphia: Lea \& Febiger; 1994. p. 3-24.

20. Cain BS, Meldrum DR, Joo KS, et al. Human SERCA2a levels correlate inversely with age in senescent human myocardium. J Am Coll Cardiol 1998;32:458-67.

21. Slama M, Susic D, Varagic J, et al. Diastolic dysfunction in hypertension. Curr Opin Cardiol 2002; $17: 368-73$.
22. Lewis JF, Spirito P, Pelliccia A, Maron BJ. Usefulness of Doppler echocardiographic assessment of diastolic filling in distinguishing "athlete's heart" from hypertrophic heart disease. Br Heart J 1992;68: 296-300.

23. Zannad F, Dousset B, Alla F. Treatment of congestive heart failure: interfering the aldosterone-cardiac extracellular matrix relationship. Hypertension 2001;38:1227-32.

24. Brilla CG, Funck CR, Rupp H. Lisinopril-mediated regression of myocardial fibrosis in patients with hypertensive heart disease. Circulation 2000;102:138893.

25. Brustsaert DL, Fransen P, Andries LJ, De Keulener GW, Sys SU. Cardiac endothelium and myocardial function. Cardiovasc Res 1998;38:281-90.

26. Angeja B, Grossman W. Evaluation and management of diastolic heart failure. Circulation 2003;107: 659-63.

27. Dickstein K. Natriuretic peptides in detection of heart failure. Lancet 1998;351:4.

28. Cowie M, Struthers A, Wood D, Coats A, Thompson S, Poole-Wilson P. Value of natriuretic peptides in assessment of patients with possible heart failure in primary care. Lancet 1997;350:1347-51.

29. Dao Q, Krishnaswamy P, Kazanerga R, Harrison A, Amirnovin R, Lenert L. Utility of B-type natriuretic peptide in the diagnosis of congestive heart failure in an urgent-care setting. J Am Coll Cardiol. 2001;37: 379-85.

30. Hunt SA, Baker DW, Chin MW, et al. ACC/AHA guidelines for the evaluation and management of chronic heart failure in the adult: executive summary. J Heart Lung Transplant 2001;21:189-203.

31. How to diagnose diastolic heart failure. European Study Group on Diastolic Heart Failure. Eur Heart J 1998;19:990-1003.

32. Zile MR, Gaasch WH, Carroll JD, et al. Heart failure with a normal ejection fraction: is measurement of diastolic function necessary to make the diagnosis of diastolic heart failure? Circulation 2001; 104:779-82.

33. Kitzman DW. Heart failure with normal systolic function. Clin Geriatr Med 2000;16:489-512.

34. Kitzman DW, Brudbaker PH, Anderson RA, et al. Exercise training improves aerobic capacity in elderly patients with diastolic heart failure: a randomized, controlled trial [abstract]. Circulation 1999; 100:296.

35. Effect of enalapril on survival in patients with reduced left ventricular ejection fractions and congestive heart failure. The SOLVD Investigators. N Engl J Med 1991;325:293-302.

36. Effects of enalapril on mortality in severe congestive heart failure. Results of the Cooperative North Scandinavian Enalapril Survival Study (CONSENSUS). The CONSENSUS Trial Study Group. N Engl J Med 1987;316:1429-35. 
37. Oren S, Grossman E, Frohlich ED. Reduction in left ventricular mass in patients with systemic hypertension treated with enalapril, lisinopril or fosenopril. Am J Cardiol 1996;77:93-6.

38. Lorell BH. Cardiac renin-angiotensin system in cardiac hypertrophy and failure. In: Lorell BH, Grossman $W$, editors. Diastolic relaxation of the heart: the biology of diastole in health and disease, ed 2. Boston: Kluwer Academic Publishers; 1994. p. 91-100.

39. Aronow WS, Kronzon I. Effect of enalapril on congestive heart failure treated with diuretics in elderly patients with prior myocardial infarction and normal left ventricular ejection fraction. Am J Cardiol 1993; 71:602-4.

40. Wachtell K, Bella JN, Rockkedal J, et al. Change in diastolic left ventricular filling after one year of antihypertensive treatment: the losartan intervention for endpoint reduction in hypertension (LIFE) study. Circulation 2002;105:1071-6.

41. Warner JG, Metzger DC, Kitzman DW, Wesley DJ, Little WC. Losartan improves exercise tolerance in patients with diastolic dysfunction and a hypertensive response to exercise. J Am Coll Cardiol 1999; 33:1567-72.

42. Andersson B, Caidahl K, di Lenarda A, et al. Changes in early and late diastolic filling patterns induced by long-term adrenergic $\beta$-blockade in patients with idiopathic dilated cardiomyopathy. Circulation 1996;94:673-82.

43. Bonow RO, Dilsizian V, Rosing DR, Maron BJ, Bacharach SL, Green MV. Verapamil-induced improvement in left ventricular diastolic filling and increased exercise tolerance in patients with hyper- tropic cardiomyopathy: short- and long-term effects. Circulation 1985;72:853-64.

44. Bonow RO, Leon MB, Rosing DR, et al. Effects of verapamil and propranolol on left ventricular systolic function and diastolic filling in patients with coronary artery disease: radionuclide angiographic studies at rest and during exercise. Circulation 1982;65: 1337-50.

45. Udelson J, Bonow RO. Left ventricular diastolic function and calcium channel blockers in hypertrophic cardiomyopathy. In: Gaasch WH, LeWinter MM, editors. Left ventricular diastolic dysfunction and heart failure. Philadelphia: Lea \& Febiger; 1994. p. 455-64.

46. Vasan RS, Benjamin EJ, Levy D. Congestive heart failure with normal left ventricular systolic function. Arch Intern Med 1996;156:146-56.

47. Nagano R, Masuyama T, Lee JM, et al. Prediction of changes in cardiac output in association with preload reduction therapy in patient with hypertensive heart failure. Cardiovasc Drugs Ther 1997;11:49-56.

48. Van Kraaij DJ, Jansen RW, Bouwels LH, Gribnau FW, Hoefnagels WH. Furosemide withdrawal in elderly heart failure patients with preserved left ventricular systolic function. Am J Cardiol 2000;85: 1461-6.

49. Pitt B, Zannad F, Remme WJ, et al. The effect of spironolactone on morbidity and mortality in patients with severe heart failure. N Engl J Med 1999; 341:709-17.

50. Grandi AM, Imperiale D, Santillo R, et al. Aldosterone antagonist improves diastolic function in essential hypertension. Hypertension 2002;40:647-52. 